Crítica de poesia 



\section{Para quê poetas?}

\section{CARLOS FELIPE MOISÉS I}

$\mathrm{N}$

O SÉTimo segmento da longa elegia "Brot und Wein" [Pão e vinho], Friedrich Hölderlin (1959, p.215-17) pergunta: "Para quê poetas em tempo de penúria?", indagação que será largamente glosada, por poetas e pensadores, século XX adentro, a ponto de seus sentidos possíveis se emaranharem, oscilando entre a clareza desconcertante e a obscuridade indecifrável. Mas não está em meus propósitos investigar a fortuna crítica do tema tão caro ao poeta alemão. Para o que me interessa, de momento, uma breve síntese, necessariamente simplificadora, será suficiente.

O "tempo" a que se refere Hölderlin não é o das circunstâncias históricas, ou das vicissitudes político-econômicas, germânicas ou europeias, da virada do século XVIII para o XIX, mas um tempo mais amplo, que se alastra desde o início da nossa Era, esse largo tempo ao longo do qual o homem, entregue à sua própria sorte, não tem feito senão lamentar a morte dos deuses: Héracles, Dioniso, Cristo. É o tempo da reductio ad hominem, a condição humana condenada a se avaliar pela sua própria medida, já que se torna virtualmente impossível fazê-lo com base em qualquer medida menos precária; um tempo cuja "penúria" se agrava, na proporção em que a realidade histórica se incumbe de dar formas cada vez mais proeminentes à profética assertiva de Protágoras: "O homem é a medida de todas as coisas".

Hölderlin se filia a essa espécie de Renascimento tardio, de sinal trocado, que foi o movimento conhecido como "Sturm und Drang", introduzido na metade do século XVIII, na Alemanha, por Goethe, Schiller e outros. Ao contrário da euforia que, dois séculos antes, brotara do Humanismo italiano, logo espalhando-se por toda a Europa mediterrânea, o "Sturm und Drang" germânico, partindo da mesma constatação da grandiosidade da cultura helênica, não acredita em momento algum que essa possa vir a "renascer", não acredita que algum "valor mais alto", como diz Camões, possa emergir deste mundo reduzido à pálida medida humana. Na longa noite de trevas em que se encontra, como lemos em Hölderlin, o homem não descortina em seus horizontes senão o imenso vazio espiritual deixado pela morte dos deuses, das crenças e das "medidas" antigas, irrecuperáveis, em face das quais o que veio a seguir é só desoladora decadência, "tempo de penúria". Na abertura do mesmo sétimo segmento de "Pão e vinho", Hölderlin exclama: "Aber Freund! wir kommen zu spät" ["Mas amigo! viemos tarde demais"], tarde demais para o tempo dos deuses, cedo demais para o tempo dos homens.

Heidegger é talvez o pensador que mais demorada atenção dedicou ao fundo pessimismo aí implicado. Refletindo sobre aquela indagação hölder- 
liniana, o filósofo afirma: "na atualidade, já mal compreendemos a pergunta. Como havemos de compreender a resposta que Hölderlin lhe dá?". Mais adiante: "Num tempo de penúria como o nosso, o homem sequer chega a se dar conta da própria penúria, a indigência se faz obscura para o próprio indigente. Essa incapacidade é o que há de mais absolutamente indigente em nosso tempo" (Heidegger, 1960, p.224-5).

Mas recensear as mutações poéticas e filosóficas dessa ideia de um longo "tempo de penúria" nos levaria longe demais, podendo também levar-nos, quem sabe, a parte alguma. O propósito desta breve referência a Hölderlin é apenas fornecer uma pista para a compreensão da bela coletânea de poemas $O$ livro de Scardanelli, de Érico Nogueira (2008). Perguntará o leitor: que tem a ver essa pequena erudição germano-helenista com os poemas de estreia de um jovem autor brasileiro? Responder "tudo" seria evidente exagero, mas é possível afiançar que tem a ver, sim.

De início, lembremos que, por volta dos seus trinta anos, após toda uma existência de desencontros e infortúnios, Hölderlin foi diagnosticado como "louco", sofreu uma internação que só fez agravar seu estado, e foi considerado incurável, por médicos que lhe deram não mais que dois ou três anos de vida. Em 1807, pouco depois da internação, o poeta encontrou abrigo, em Tübingen, na propriedade de um mestre-carpinteiro de nome Zimmer, seu admirador, que lhe cedeu um pequeno aposento, do qual ele raramente se afastou, até o fim... mais de trinta anos depois.

No curso de sua longa noite de loucura, o poeta continuou a escrever, pouco, é verdade, sempre sob pseudônimos invulgares, dos quais o mais frequente foi exatamente Scardanelli, o mesmo nome que, quase dois séculos depois, é convocado para figurar no título do livro de estreia do poeta brasileiro. No caso do alemão, a relação entre esquizofrenia (na época foi esse o diagnóstico) e o uso de pseudônimos parece inescapável. Ao longo das três décadas durante as quais esteve sob os cuidados do carpinteiro Zimmer, Hölderlin recebeu raras visitas: poucos poetas, amigos do tempo de juventude, alguns curiosos, um ou outro leitor anônimo. Um deles, certa vez, apareceu-lhe carregando um exemplar de Hyperion, publicado anos antes, para comprovar a veracidade de sua admiração. Hölderlin folheou o volume, por um momento, e logo exclamou: "Der Name ist gefälscht. Ich habe nie Hölderlin geheissen, sondern Scardanelli!" ["Esse nome é falso. Eu nunca me chamei Hölderlin, mas Scardanelli"]. Já as relações entre esse instigante "caso" literário e o jovem estreante brasileiro é o que tratarei de deslindar, mais adiante.

Paul Veyne, o grande historiador da cultura, assevera que, desde Petrarca (1304-1374), todos nós, leitores de poesia, nos habituamos a divisar, no recesso de toda obra poética, a voz particular de um ego que expõe publicamente suas dores e alegrias pessoais, historicamente datadas. A partir daí, ao contrário do 
que ocorria na Antiguidade, quando era aceita como forma de encenação, a poesia lírica passa a ser encarada como confidência íntima (Veyne, 1983, p. 254 passim). Camões, nosso petrarquista exemplar, colabora para endossar e reforçar o hábito, alertando-nos: "Sabei, pois, que segundo o amor tiverdes / Tereis o entendimento dos meus versos". Desde então, o primado da voz particular e da subjetividade, que irmana sujeito-poeta e sujeito-leitor, tem sido encarado como verdade inquestionável, segunda natureza, indissociável do lirismo. Poesia passa por ser o entrelaçamento de subjetividades, sensíveis e permeáveis, propiciado pela franqueza com que o poeta nos expõe sua subjetividade modelar. Tal franqueza faculta a todos nós o acesso a esse entrelaçamento, que nos mantém na firme convicção de que estamos fortemente ancorados na realidade (a mesma dos poetas, pois não?), quando talvez estejamos apenas a alimentar a fantasia de que assim seja, ludibriados ou pelo engenho e a arte dos poetas, ou pela força da inércia.

Hoje sabemos (a malícia pós-moderna nos põe a salvo dessa ilusão, embora não nos torne imunes a outras) que nem em Petrarca, nem em Camões, nem em nenhum dos nossos grandes poetas, antigos e modernos, o ego que nos fala em seus versos "retrata" a subjetividade ou a vida privada do cidadão responsável por esses mesmos versos. Hoje preferimos falar em "eu lírico", para contrapô-lo à conjectura de um "eu empírico", e já não exigimos do poeta a franqueza ou a "sinceridade" que dele se esperava, desde os tempos de Petrarca.

A razão é, afinal, elementar. A partir do cogito cartesiano, pouco a pouco fomos ganhando consciência de que esse ego, no qual ser e existir almejam sustentar-se, não é senão construto mental, algo que só aparece para o mundo na emergência da fala, fieira de palavras, simulacro de realidade. A linguagem humana não tem como dizer o mundo: "O mundo é a minha representação do mundo", assevera Schopenhauer, e certa pós-modernidade nos convencerá de que tudo são relatos, discursos, ficções que variam ao infinito, supostamente no encalço de uma subjacente verdade singular (a verdade do eu ou a verdade do mundo), que nos escapa. Ao proferir "eu", Petrarca, Camões, Hölderlin qualquer poeta - já não tem mais como dizer, com "sinceridade", o que lhe vai pela vida íntima. Adorno $(2009$, p.152, 159) chama a atenção para o fato de que "quanto mais soberanamente o eu se eleva sobre o ente, tanto mais ele se transforma sub-repticiamente em objeto e revoga ironicamente seu papel constitutivo. [...] Sem a alteridade, o conhecimento se degeneraria em tautologia; o conhecido seria o próprio conhecimento". O que daí provém será sempre representação figurada, simulação, tal como o fora entre os antigos e, ao que parece, nunca deixou de ser. Rimbaud admite: "Je est un autre"; se acreditarmos em Fernando Pessoa, o poeta "finge tão completamente / que chega a fingir que é dor / a dor que deveras sente".

Se não levarmos em conta o fim da ilusão de "realismo" que circularia tacitamente no intercâmbio entre o poeta e seus leitores, o livro de estreia de Érico 
Nogueira só causará estranheza, e a incômoda sensação de descentramento. Se o leitor folhear o volume à procura do "eu empírico" do jovem poeta brasileiro, à espera de confidências íntimas ou algo similar, sairá de mãos vazias, não terá um livro de poesia do tipo a que estamos habituados, mas o equivalente verbal à boneca do imaginário eslavo, dentro da qual se esconde outra, e mais outra, até que no desdobramento derradeiro se encontre o grão último, a figura de todas as figuras, da qual brotam todas as demais, mas da qual ninguém jamais pôde dar notícia.

O livro de Scardanelli não é apenas uma recolha de poemas, é a realização consciente e deliberada de uma concepção de poesia, para a qual a ideia do fim da falácia da subjetividade é uma das chaves. Inútil buscar aí o "eu empírico" do jovem autor, não que esse esteja ausente, podemos até dizer (paradoxo!) que sua presença é dominante, mas prefere expressar-se de modo evasivo, irônico, por meio de máscaras e representações metafóricas, tomadas de empréstimo não só a Hölderlin-Scardanelli, mas a outros poetas: Camões, Trakl, Rilke, Shakespeare, o Jorge de Lima da Invenção de Orfen e outros mais.

O livro de Scardanelli reúne um total de 72 poemas, distribuídos por três seções: "Livro de horas", "Cancioneiro inglês ou de Sandra Gama" e "Caderno de exercícios". Na primeira, uma voz sentenciosa e grave, mas serena, pondera sobre a inexorável passagem do tempo, que a tudo corrompe, não prometendo nenhuma certeza senão a morte, e decreta: "por isso come, bebe, goza a nitidez / de não saber se é desta, se duma outra vez". É uma voz cantante, melodiosa, empenhada em reverberar a irisada multiplicidade de formas e cores que, em sua incessante mutação, a paisagem natural oferece ao olhar atento: sombra, nuvem, chuva, sol, o vento, o raio, o barro, o verde-musgo... E é uma voz que parece amoldar-se, com naturalidade, à suave cadência dos versos decassílabos ou alexandrinos, bem medidos, muitas vezes rimados, que se alternam e se acomodam em quartetos e dísticos quase sempre regulares.

De tempos em tempos, repete-se a ordem que manda aproveitar a vida ("Por isso goza, Frederico, a parte / que do todo puder a tua arte"), com o objetivo de reiterar a inutilidade de todo esforço humano que não se concentre no instante fugidio, que não se liberte das lembranças irrecuperáveis ou das aspirações irrealizáveis. Para além da ordem expressa, porém, o que mais persuasivamente nos fala da atitude propiciadora dessa invejável sabedoria é o sereno mas firme controle da linguagem e suas formas - metros, rimas, cesuras, enjambements, estrofação - ritmos variáveis, que se intercalam e fluem com desenvoltura. É como se o poeta nos dissesse: se fores capaz de submeter as palavras ao seguro domínio de tua vontade, assim será também com tua alma inquieta e teu coração aflito. "Carpe diem" (goza os dias), ensina Horácio, pois o mais é "sonho de uma sombra". De tal matéria se faz o "Livro de horas", de Érico Nogueira. Mas não só. 
A voz que aí desfia sua estoico-epicúrea lição de vida - a declarada ou a que se esconde sob a lição de poesia - escolhe a forma da conversação, e a escolha não terá sido arbitrária. "Todo diálogo reflexivo com uma declaração poética", afirma Heidegger (1982, p.160-1), "se dá no interior da reciprocidade entre discussão e clarificação", como parece ocorrer com os ensinamentos que esse "Livro de horas" vai desfiando. E o filósofo prossegue: "Só a conversação entre poetas, só o diálogo poético com uma declaração poética pode ser considerado verdadeiro diálogo. Mas também é possível, e não raro necessário, que o diálogo se dê entre o pensar e a poesia, já que é inerente a ambos, embora diferente em cada caso, uma privilegiada relação com a linguagem".

O diálogo que então se desenrola é travado com um interlocutor único, "Frederico", nosso já conhecido Friedrich Hölderlin. Com efeito, a moldura dos poemas que formam esse "Livro de horas" em boa medida provém da série que Hölderlin compôs, depois de condenado à loucura: insistentes referências à Natureza e à passagem das estações; a candura do mesmo sentimento "ingênuo", várias vezes reiterado; a monotonia dos títulos que se repetem, obsessivos; a mesma suave simplicidade de linguagem; as datas fictícias, implausíveis, no fecho de cada composição. ${ }^{1}$ Ao que parece, tudo são indícios da "loucura" que acometeu o poeta alemão, marcas da nova identidade que assumiu. Mas não é a Hölderlin-Scardanelli que a voz do "Livro de horas" se dirige, e sim à identidade perdida desse Frederico anterior à loucura. O leitor não terá dificuldade em detectar, aí, um complexo jogo de espelhos. Antes de tentar explicá-lo, recorramos ainda uma vez ao ensinamento de Paul Veyne (1983, p.228), de quem tomo emprestado o símile do espelho:

Um poeta, desde que seja de fato poeta, nunca é sincero. Sua alma é mobiliada com certo número de sentimentos, assim como a dos outros homens; além disso, nessa mobília há também um espelho, que reflete o resto do mobiliário. Nós só pensamos no mobiliário, esquecendo que o espelho é um móvel a mais; a alma que contém esse móvel de Narciso ou de exibicionista não é igual a outra que tivesse o mesmo mobiliário, mas não tivesse o espelho. Além do quê, esse espelho fabrica aquilo que se presume que reflete.

A voz conselheira, que se dirige ao amigo Frederico, seria a de um Scardanelli "ensandecido", no entanto perfeitamente sabedor de que, em seu íntimo, ainda vive o mesmo repudiado Hölderlin, embora não o dos fatos e da inglória existência pregressa, mas o das aspirações mais elevadas, que só agora, em meio à "loucura" apaziguadora, se aproxima da posse de sua almejada plenitude. Mas a mesma voz parece ser também a de um ego alheio, nem Hölderlin, nem Scardanelli, a voz de um "eu lírico", inventado pela fantasia de um poeta brasileiro, do século Xxi, a partir de moldes horacianos, que recomendam, como já vimos, "carpe diem", e ainda "inutilia truncat" (elimina as inutilidades), não só as dos versos eventualmente mal elaborados, mas também as que corroem a alma re- 
pleta de desejos vãos; e recomendam sobretudo "fugere urbem et vivere in aurea mediocritate" (fugir da cidade e viver em áurea mediocridade ${ }^{2}$ ), conselho decisivo, de um modo ou de outro seguido pela maioria dos poetas do Ocidente.

Podemos entender, então, que a voz presente em "Livro de horas" pertence também a um "eu lírico", alheio e distante, que se dirige a certo Frederico, em cujo íntimo lateja, prestes a aflorar, o seu duplo "insano", Scardanelli, a quem caberá desfazer todas as duplicidades, retirar todas as máscaras. Mas o mesmo Frederico é também só um nome postiço, interlocutor imaginário, simultaneamente situado em Tübingen, no século XVIII, na Roma do século I antes de Cristo, ou em qualquer parte deste imenso Brasil do século XXI, onde possa encontrar um leitor atento este instigante O livro de Scardanelli. De qualquer ângulo ou perspectiva que o consideremos, o mundo continua a ser (será sempre?) o somatório improvável "deste e do outro lado", conforme anuncia o poema de abertura do "Livro de horas", em sua melodiosa alternância de decassílabos e alexandrinos:

A hora lúcida de cara dupla rebenta no desenho da planície, e até que a sombra chegue, a nuvem chegue, fica e tira o gosto acre do azedume.

Metade sim, metade não, há uma esfinge

em toda hora que interroga e finge.

Responde, Frederico, ao interrogado

e olha o mundo deste e do outro lado.

Jogo de espelhos, claro está, além do mobiliário mais ou menos comum, como diria Paul Veyne. Loucura? Esquizofrenia? A lucidez será só a contraface da insanidade, e vice-versa? Perda/busca da identidade? Realidade e/ou fantasia? A vida efetivamente vivida e/ou sua imagem refletida em espelhos que refletem outros espelhos? O mundo é só a minha representação do mundo, como quer Schopenhauer, ou existirá de fato um mundo, aí, dado, comum a todos nós?

Adorno (2009, p.158) ensina que

o objeto só pode ser pensado por meio do sujeito, mas sempre se mantém como outro diante dele; o sujeito, contudo, segundo sua própria constituição, também é antecipadamente objeto. Não é possível abstrair o objeto do sujeito, nem mesmo enquanto ideia, mas é possível esvaziar o sujeito do objeto. Também pertence ao sentido da subjetividade ser objeto, mas não do mesmo modo como ao sentido da objetividade ser sujeito.

E a quem isso tudo dirá respeito? A que "tempo de penúria", enfim, remete a instigante viagem que Érico Nogueira empreende à intimidade desse mítico Hölderlin-Scardanelli?

Caso as demais seções confirmem os procedimentos adotados em "Livro de horas", O livro de Scardanelli pode ser lido, quem sabe, à luz da alegoria: o alvo verdadeiramente visado pelo enunciado dos versos, e pelos motivos que 
lhes dão origem, talvez não seja o que parece, talvez estejamos diante de um tríptico espelhado, onde se refletem outro tempo e outro lugar, jamais declinados nominalmente, mas que se tornam, à medida que avançamos, cada vez mais reveladores da "penúria" em que hoje, analogamente, nos encontramos, já que não a reconhecemos como tal, à semelhança da "indigência" que Heidegger imaginou ter sido denunciada na antiga elegia "Brot und Wein". E aí temos uma resposta à indagação "Para quê poetas em tempo de penúria?": para devolver alguma consciência aos que a perderam de todo.

A unidade temática do "Livro de horas", reforçada pela metrificação uniforme, é ainda mais acentuada no "Cancioneiro inglês ou de Sandra Gama", sequência de 24 sonetos amarrados entre si pela presença obsessiva de um eu que, em vez de se voltar para fora, em busca de diálogo com algum interlocutor privilegiado, como o Frederico da seção anterior, volta-se para dentro, em regime de autoindagação, no encalço da apreensão de sua ipseidade: "o que pondero, o que lamento - é meu, / diz só respeito à praga do meu mal”, como lemos no soneto de abertura. O poeta parece seguir o conselho de Adorno (2009, p.302): "Se a dialética negativa reclama a autorreflexão do pensamento, então isso implica manifestamente que o pensamento também precisa, para ser verdadeiro, hoje em todo caso, pensar contra si mesmo". Mas antes de entrarmos no recesso dessa vertente, cumpre chamar a atenção para os expedientes a que a série recorre, ao mesmo tempo protocolares e rebeldes, em face da relativa liberdade com que aí são manipuladas as formas clássicas.

O que temos nesse "Cancioneiro" é o que conhecemos como soneto "inglês" ou "shakespeariano": três quartetos e um dístico. Nesse formato, o travamento silogístico da tradição camoniana (premissa maior, premissa menor, conclusão) de algum modo permanece, mas uma importante variação é introduzida: a conclusão tende a se concentrar no dístico final. O soneto, assim, continua a ter duas subunidades, mas enquanto a segunda se reduz à brevidade do dístico, a primeira se espraia pela abundância de doze versos, deixando de ser mandatório o trâmite que conduz do geral para o particular: o poeta agora pode, já nos primeiros versos, entrar diretamente no seu tópico de interesse mais imediato.

É essa a forma adotada por Érico Nogueira, na segunda seção do livro, deixando clara a importância atribuída ao dístico final, vitorioso e conclusivo, sentencioso, com sua cantante rima emparelhada: "A boca antiga, então, se mostra hábil / para falar do que corrói o lábio"; "Ó mar salgado, aonde, aonde chego / que o sal tempera meu desassossego?"; "Que douta fauna, fauna do oceano, / da pesca lírica, sonoro engano" - e assim por diante.

Se os sonetos desse "Cancioneiro" são ingleses, não assim com os quartetos, que oscilam, na trama sintática e no variável esquema de rimas, entre a forma shakespeariana e a camoniana, às vezes aparecendo como uma só estrofe de doze versos; outras, uma oitava seguida de uma quadra, ou vice-versa; e chegam 
à "ousadia" da rima toante e até mesmo à "heresia" do verso branco, sem rima, vale dizer solto e abandonado, para horror da ortodoxia conservadora. Essa é uma das características, aliás, a impedir que a maestria artesanal do poeta seja tachada de mero e anacrônico divertissement metrificatório.

Repare-se nos dois primeiros quartetos do oitavo soneto, em que a ousada rima toante (fórmula/norma) e os heréticos versos brancos (boca/estúpida), na primeira metade, são compensados pela retomada do esquema canônico, na segunda metade:

Se eu aprendesse a dispensar a fórmula, as correntes que amarram minha boca, reproduzindo, maquinal e estúpida, a lei do mesmo jogo, a mesma norma de não dizer bem quando digo "digo", ou, ao invés, dizer ao não dizer - então seria cômodo, a meu ver, tratar do que é amigo e inimigo.

O tópico que aí aflora é claro: que relação deve/pode manter com a tradição, isto é, com fórmulas \& normas, o poeta cioso de sua marca própria? A obediência estrita à tradição "maquinal e estúpida" não levará a marca alguma, muito menos própria; já o rompimento radical propiciará, quem sabe, essa marca, mas impalpável e incerta, a vagar, perdida, no imensurável vazio de si mesma. Partindo de uma primeira tomada de consciência ("a minha nau já vai deixar o cais, / vazia da abundância que juntei / e junto sempre e sempre e mais e mais / e nada somos pelo que somei”), o poeta acaba por concluir, a sós consigo:

...porque não me conheço

e nunca achei no espelho meu reflexo, isso não quer dizer que não mereço querer além do costumeiro nexo:

algo que quero porque não é meu, mas que só eu vivi - de mim -, só eu.

Mas atentemos para o fato de que, além de ser "inglês", esse "Cancioneiro" é também "de Sandra Gama". Quem vem a ser tal figura? Pede a tradição que a perquirição existencial do poeta lírico, no encalço de sua identidade verdadeira, tenha sempre como núcleo e epicentro a figura primordial da musa inspiradora: Petrarca e sua Laura, Dante e sua Beatriz, Camões e sua Natércia, Hölderlin e sua Diotima. Assim também o jovem poeta e sua Sandra Gama... Bem-amada real ou "amante de escrivaninha", como diria Paul Veyne? Ao contrário de seus antecessores ilustres, que insistiram em vender a ilusão (para si mesmos, primeiro, antes de a venderem aos crédulos leitores), o poeta brasileiro não hesita em admitir, em tom farsesco:

Cansei-me da empolada elocução

e de chorar quem eu não conheci. 
[...] Deus me livre

de chatear ainda o meu leitor

com essa tal de Sandra Gama, livre,

ainda que ela seja meu amor;

amor de quem eu nunca vi mais gorda,

e que, por isso, me entalou na porta.

Tudo não passa de encenação, reconhecerá o leitor.

Se o poeta não sustentar suficientemente a ficção pessoal estabelecida de início, o leitor a esquecerá, se não for filólogo, e as figuras recairão no anonimato. [...] O poeta não se propõe retratar uma mulher que conheceu, e contar seus amores; ele retrata um gênero de vida. [...] Onde se viu que a sinceridade é uma qualidade estética? Para acreditar nisso, é preciso ter mais gosto pelos mexericos, digamos, pela psicologia, do que pelo sentido literário. (Veyne, 1983, p. 97, 101, 106)

Paul Veyne se refere à Clódia de Catulo, à Cíntia de Propércio, à Délia de Tibulo... Mas por que não incluir nesse rol a Sandra Gama de Érico Nogueira? “Autores são atores, livros são encenações”, e quem o diz, já agora, não é um historiador da Antiguidade clássica, mas um poeta moderno, Wallace Stevens (1965, p.146).

Se assim é, dirá o atento leitor, que diferença faz? Ao ler nosso Petrarca, nosso Dante, nosso Camões, nosso Hölderlin, gostamos de ser enganados, gostamos de acreditar na existência real de Lauras e Beatrizes, como se fossem de carne e osso e não imagens quase transparentes, imortalizadas em versos raros. Por que, então, nos versos afinal nada cerimoniosos de Érico Nogueira, por vezes desconcertantemente sinceros, desfeita a fantasia, não podemos ler apenas a imortalidade de um sentimento comum, ainda que Sandra Gama e o mais sejam só encenação? Caso ao leitor incomode o fato de o poeta não fazer segredo disso, ele próprio o justifica, no diálogo suposto no soneto de número 19, em tom mais uma vez farsesco e coloquial:

"Depois de ler mais de duzentos versos,

você me diz, de cara mal lavada, que isso que li são invenções perversas, que você não conhece a sua amada?" "É, bem, ah, sabe, né, a gente, enfim, confesso: não conheço a Sandra Gama.

Seu nome é este, e ela existe sim, mas não sei onde, em Portugal, na Espanha, ou em esquivo, apenas, pensamento, escravo que só foge do seu dono, engole vida mas defeca vento, e assalta a casa-grande pelo sono. Por isso não conheço com quem lido: pois de mim mesmo sou desconhecido." 
No curso desse "Cancioneiro", caso pairasse alguma dúvida, reaparece uma única vez (mais acertado seria dizer: finalmente aparece) uma figura sobejamente conhecida, o "doido" Scardanelli, anunciado no título do livro, mas na verdade jamais mencionado nominalmente, até aqui, em nenhum verso do livro todo. E aparece justamente para se igualar a essa inefável Sandra Gama - "sombras mentais", como nos revela o soneto 22:

Para falar convém que haja um sopro ou coisa assim, não sei dizer ao certo; convém que a vida arda mesmo em dobro sem que haja vida mesmo por perto; convém que Scardanelli e Sandra Gama, sombras mentais, ensombrem corpo e cama.

Quanto ao poeta, esse continua à procura de si mesmo, tal como se propusera de início, e não se peja em recorrer ao leitor, para que esse o socorra, no transe comum: "não sei se é flor, e menos quanto vale: / quem crê sabê-lo, por favor me fale".

A terceira parte do livro, "Caderno de exercícios", não tem o mesmo senso de unidade das anteriores, nem no que se refere aos temas e motivos, à dicção e ao tom geral, nem aos expedientes formais: tudo aí é variação e heterogeneidade, passando ao leitor exatamente a impressão de exercícios ou experimentos singulares, em múltiplas direções. Alguns temas e interesses, já percorridos, aqui reaparecem, como os ligados à Natureza e ao imaginário marítimo ou ao "carpe diem" horaciano; outros surgem pela primeira vez, como os profetas do Aleijadinho ou a figura de Narciso. As formas variam, consideravelmente, desde a regularidade métrica e estrófica dos decassílabos, que às vezes alternam com hexassílabos, agrupados em quartetos ou quintetos, até a irregularidade das composições em verso livre, poucas, mas significativas, pois representam o que há de mais potencialmente experimental na poética de Érico Nogueira, que não esconde seu apego preferencial às formas fixas.

Aí se delineia, quem sabe, o conflito básico que move não só esse "Caderno", mas o livro todo, entre o sujeito-poeta, desejoso de independência, e a tradição veneranda, que em princípio induziria ao retraimento e à impessoalidade. Mas nada aí denuncia quer a subserviência de quem se autoanula, quer a rebeldia de quem se empenha em exacerbar um ego demasiado cioso de si mesmo. Tratando, por exemplo, de algo tão propício a essa exacerbação, como é o tema de Narciso, ainda assim o poeta prefere adotar o distanciamento estratégico de quem apenas discorre a respeito, na tentativa de se desviar do tanto de autoconfissão que aí se esconde: "perscruta então o céu como um espelho / e vê que certa estrela é como um traço / do rosto mais secreto, o teu".

O conflito, enfim, se põe em termos de aguda consciência dos contrários (a "dialética negativa", tão cara a Adorno), que ao mesmo tempo se repelem e 
se complementam: o já consagrado e o ainda não explorado, a disciplina regrada e o livre improviso, a certeza e o risco, "o amigo e o inimigo", e assim por diante. Consciência, no caso, significa a certeza de que tentar anular qualquer dos polos em conflito resultaria em perda irreparável. O poeta se reconhece "condenado", embora por livre escolha, a conviver com ambos, como quando se desdobra num "tu" fictício, alter ego inarredável, para reforçar a mágoa da autocondenação:

Daquela funda treva não se sabe como voltar, a altura não se anela: te resta o mar pisado e repisado, pescar, talvez, o que já foi pescado.

Essa mão ergue, amigo, num instante, outra mão em seguida o arruína:

por isso não há rota, e o navegante

perde o que teve, ganha o que não tinha.

Aparecendo no final do volume, esse "Caderno" será entendido naturalmente como ponto de chegada. Tendo percorrido duas experiências centradas na disciplina interior, no esforço da unificação de núcleos reiterados em regime de cumplicidade temática e formal, o poeta agora se entrega à livre experimentação de rumos variados. Mas essa seria uma explicação simplificadora, baseada no pressuposto de que a ordenação das seções corresponde à ordem natural da composição dos poemas. É possível também imaginar que esse "Caderno de exercícios", embora fecho do livro, seja um ponto de partida, espécie de "aquecimento" preparatório à experiência poética mais ambiciosa, empreendida nas seções anteriores. O mais avisado, portanto, é aceitar essa terceira seção como ponto de chegada e de partida, concomitantemente, a insinuar que o conflito de base atrás delineado é ao mesmo tempo causa e efeito - dinamismo exemplar, representação de um impasse que está longe de ser resolvido e incessantemente se repõe e se refaz, tal como a vida, tal como a poesia verdadeira - alfa e ômega, boca a morder a própria cauda, como o uróboro da lenda.

O "exercício" derradeiro, fecho do livro todo, mas ao mesmo tempo matriz de onde tudo proveio, é não por acaso uma singela tradução de um poema de Hölderlin. No posfácio, o poeta se manifesta a respeito, afirmando que a terceira parte do livro "termina com uma tradução, no sentido mais usual do termo, de 'Lebenslauf', do mesmo Hölderlin - o que não significa que não a tenha ajustado às minhas conveniências, que não revelo aqui nem alhures". Não cometamos, pois, a indiscrição de tentar adivinhar quais seriam as "conveniências" do poeta. Limitemo-nos a colocar, lado a lado, a sua tradução, visivelmente livre e abreviada, e uma tradução mais antiga, virtualmente literal, não do poema todo, mas apenas das duas primeiras estrofes, matéria suficiente, quem sabe, para satisfazer a curiosidade do leitor. 
Primeiro, a tradução fiel, de Paulo Quintela, talvez "inconveniente", no sentido de contrária às preferências do jovem poeta brasileiro, já que segue de perto a modulação da fala hölderliniana:

Coisas maiores querias tu também, mas o amor

A todos vence, a dor curva ainda mais,

E não é em vão que o nosso círculo

Volta ao ponto donde veio!

Para cima e para baixo! Não sopra em noite sagrada,

Onde a Natureza muda medita dias futuros,

Não domina no Orco mais torto

Um direito, uma justiça também? (Hölderlin, 1959, p.135)

Agora a tradução "infiel" do autor brasileiro, que extrai do texto de origem algo que continua a serviço do traduzido, mas passa a servir também às suas conveniências de poeta-tradutor:

Querendo ser maior, vi que o amor

rebaixa tudo, a cólica nos curva;

o nosso arco não acerta a fruta

se a sua corda não estoura.

Em noite densa, em que não luz a lua, quando a Natura sonha um outro astro, me achei no fundo Orco, tão bizarro, tão arredio ao nosso olho.

E podemos ficar por aqui. Seguir adiante seria roubar do leitor o prazer de descobrir por sua conta os muitos segredos desse O livro de Scardanelli, auspiciosa estreia do jovem poeta Érico Nogueira.

\section{Notas}

1 O leitor interessado no "Ciclo Scardanelli" poderá recorrer à tradução de Maria Teresa Dias Furtado, disponível em <www.snpcultura.org/impressao_holderlin_ciclo_scardanelli.html> Acesso em: 15 out. 2008.

2 Tal é o sentido literal de mediocritas, mas para Horácio e Epicuro (tantos séculos antes da vitoriosa ascensão burguesa), o termo tinha só conotações positivas: moderação, harmonia, meio-termo, ponderado equilíbrio entre extremos.

\section{Referências}

ADORNO, T. Dialética negativa. Trad. Marco A. Casanova. Rio de Janeiro: Zahar, 2009.

HEIDEGGER, M. Holzwege / Sendas perdidas. Trad. José Rovira Armengol. Buenos Aires: Editorial Losada, 1960. 
HEIDEGGER, M. Language in the poem: a discussion on Georg Trakl's poetic work. In: __. On the way to language. Trad. Peter D. Hertz. San Francisco: Harper \& Row, 1982.

HÖLDERLIN, F. Poemas. Trad. Paulo Quintela. Coimbra: Atlântida, 1959.

NOGUEIRA, E. O livro de Scardanelli. São Paulo: É Realizações, 2008.

STEVENS, W., Adagia. In: James Scully (org.), Modern poetics, New York, McGraw Hill, 1965, p. 146.

VEYNE, P. L'élegie érotique romaine: l'amour, la poésie et l'Occident. Paris: Seuil, 1983.

RESUMO - A estreia do poeta brasileiro Érico Nogueira, O livro de Scardanelli, retoma a antiga questão das relações entre poesia e loucura, compondo um intenso jogo ficcional criado a partir do pseudônimo adotado por Hölderlin, tomado como interlocutor de um tocante diálogo, de alta elaboração estética, em torno condição humana.

PALAVRAS-CHAVE: Poesia, Loucura, Verdade, Fingimento, Decadência.

ABstraCT - The debut of Brazilian poet Érico Nogueira, O livro de Scardanelli [The book of Scardanelli], rekindles the old question of the relationship between poetry and madness by composing an forceful fictional game with the pseudonym adopted by Hölderlin, who becomes the interlocutor in a touching and aesthetically sophisticated dialogue about the human condition.

KErWords: Poetry, Madness, Truth, Falsehood, Decadence.

Carlos Felipe Moisés é poeta (Disjecta membra, 2014) e crítico literário (Frente é verso, 2014), professor aposentado do Departamento de Letras Clássicas e Vernáculas, FFLCH-USP.@-carlos_moises@uol.com.br

Recebido em 10.2.2015 e aceito em 20.2.2015.

${ }^{\text {I }}$ Faculdade de Filosofia, Letras e Ciências Humanas, Universidade de São Paulo, São Paulo/SP, Brasil. 
